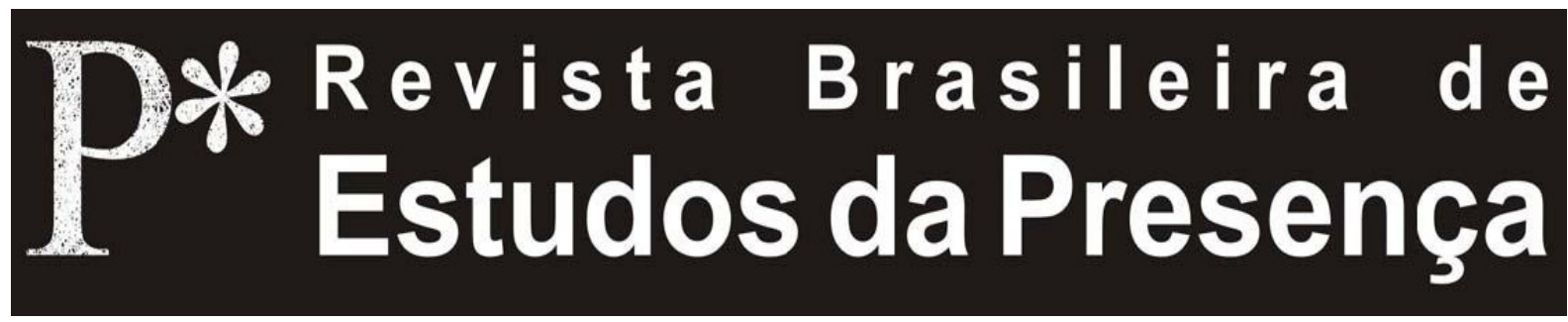

DOI - http://dx.doi.org/10.1590/2237-266035076

ISSN 2237-2660

\title{
História de um Adereço: do quotidiano ao palco
}

\author{
Filipa Malva \\ Universidade de Coimbra - Coimbra, Portugal
}

RESUMO - História de um Adereço: do quotidiano ao palco - Um objeto do quotidiano pode ser usado em performance como mediador entre a realidade do palco e a ficção da narrativa. Pode movimentar-se entre estes dois universos, permitindo aos performers percorrer a fronteira entre os espaços de representação e de ficção, tal como são definidos por Gay McAuley em Space in Performance - reposicionando mental e espacialmente a narrativa. $\mathrm{O}$ modo através do qual os performers conseguem esta modificação é através da manipulação da nossa percepção da função, escala, som e estética do objeto. O performer usa as características originais do objeto, como a cor, textura, forma e função, como pistas, reenquadrando-as, para estabelecer novas relaçóes dentro da narrativa principal. Este processo de transformação cria uma relação fluída entre a dramaturgia e a cenografia, permitindo aos performers, cenógrafo, encenador e, claro, espectadores, partilhar uma criação teatral em emergência.

Palavras-chave: Cenografia. Adereço. Practice-as-research. Objeto. Quotidiano.

ABSTRACT - A Prop's Story: from everyday life to the stage - An everyday object can be used in performance as a mediator between the reality of the stage and that of the narrative. It can go back and forward between these universes, allowing performers to play with the boundaries between presentational and fictional spaces, as defined by Gay McAuley in Space in Performance - re-positioning the narrative, either mentally or spatially. Performers can achieve this change by manipulating the perception of an object's function, scale, sound and aesthetics. The performer uses the object's original characteristics, such as colour, texture, form and design purpose, as potential clues, reframing them to establish new links with the main narrative. This process of transformation makes for a fluid scenography/dramaturgy relationship where performers, scenographer and, of course, spectators share the experiencee an emerging theatrical creation.

Keywords: Scenography. Stage Property. Practice-as-research. Object. Everyday.

RÉSUMÉ - L'Histoire d'un Accessoire de Théâtre: du quotidien à la scène - Un objet du quotidien peut être utilisé comme médiateur entre la réalité de la scène et la fiction du récit. Il peut circuler entre ces deux univers, permettant aux performers de jouer avec les limites de l'espace de la représentation et celui de la fiction, tels qu'ils sont définis par Gay McAuley dans Space in Performance - générant ainsi un déplacement mental ou spatial du récit. Ce changement peut être effectué par les artistes grâce à l'altération de la perception, de la fonction, de l'échelle, du son et de l'esthétique de cet objet. Le performer utilise les caractéristiques d'origine de l'objet, comme la couleur, la texture, la forme et la fonction, comme des indices permettant d'établir de nouvelles relations à l'intérieur du récit principal. Ce processus de transformation crée une relation fluide entre la dramaturgie et la scénographie offrant aux performers, au scénographe, au metteur en scène et, bien sûr, aux spectateurs, la possibilité de partager l'expérience d'une création théâtrale en cours.

Mots-clés: Scénographie. Accessoire. Practice-as-research. Objet. Quotidien. 


\section{Introduçáo}

Alan Read na introdução de Theatre and Everyday Life fala da coexistência entre o quotidiano e a imaginação. Citando Peter Brook, ele diz que a polaridade convencional entre estes dois conceitos é "tanto pouco saudável como mentirosa", acrescentando que "se existe uma coexistência entre a imaginação e o quotidiano, é tempo de discutirmos esta dialética" (1993, p. 14). Neste ensaio estudo exemplos de adereços de teatro que surgiram da aplicação de imaginação ao quotidiano. Os objetos usados em performance são um aspecto pouco desenvolvido na investigação na área da cenografia, mesmo que sejam usados em quase todos os espetáculos e que, em conjunto com os figurinos, sejam frequentemente os únicos objetos em palco. Darwin Reid Payne explica que,

[...] a relação de um performer com um adereço é um elemento frequentemente negligenciado pela encenaçáo, interpretação e cenografia. [...] Os adereços podem ser, e muitas vezes são, a razão de um pensamento, a materialização de uma emoção que não poderia ser descrita mas apenas demonstrada. Para ser mais preciso, os adereços são frequentemente o objetivo da cena aos quais nenhuma palavra ou combinaçáo de palavras poderá ser acrescentada. Mais do que isto, um adereço pode precipitar uma mudança significativa no desenvolvimento de uma narrativa, modificando a direção de uma peça de um modo significativo (1993, p. 122).

É a relação entre performer e objeto que indica 'uma nova direção para uma peça'. Mesmo se um objeto pode sugerir uma ideia simplesmente por ser colocado em palco, é a sua interação com o performer que lhe dá significado. Por vezes um objeto pode amplificar um gesto, quer física quer mentalmente. Outras vezes, o movimento do performer ativa o objeto para lá da sua função original. É esta relação bilateral que faz expandir o espaço ficcional da performance. O que me interessa nesses objetos é precisamente o processo pelo qual eles podem ser observados, manipulados e modificados pelos performers através de um processo de improvisaçáo em ensaio. Deste ponto de vista, objetos do quotidiano são especialmente interessantes porque pedem que os performers estabeleçam uma relação entre o quotidiano e o imaginado.

Os adereços podem ser construídos de propósito para um espetáculo ou podem ser ready-made. Os primeiros são cuidadosamente desenhados para uma produção; os segundos são objetos do quo- 
tidiano reutilizados para uma performance. Assim que escolhemos começar com um objeto do quotidiano, temos imediatamente um adereço com várias camadas de significado - a primeira camada é a sua funçáo original, que tem a capacidade de relacionar o nosso reconhecimento com a nossa imaginação. Num momento específico do ensaio, cremos na possibilidade do objeto se transformar em algo mais e este salto da imaginação permite-nos ir mais além no processo de improvisação. Read diz-nos que

[...] o teatro apropria-se do conteúdo, das relaçóes, do humor, da surpresa, do choque, da intimidade e do voyeurismo do quotidiano. Toma para as suas formas unidades de tempo e lugar, situaçóes domésticas, paisagens e padrôes de discurso que são frequentemente identificáveis porque são retirados da vida do dia-a-dia, e são celebrados precisamente porque, de algum modo, são verdadeiros para o mundo (1993, p. 51).

Num processo de ensaio por improviso, os objetos são escolhidos pelo encenador, pelo cenógrafo e pelos atores como uma forma de provocar mudança e provocar o nascimento de ideias relacionadas com uma tarefa em particular ou uma narrativa. Do mesmo modo, Gay McAuley chama a atençáo para o fato de que,

[...] no teatro físico ou de performance, onde pode existir um conteúdo ficcional mínimo e nenhum texto preexistente para ser interpretado ou feito significante, os objetos têm um papel ainda mais poderoso. A presença física do objeto, o seu papel na definição do espaço da performance e as oportunidades de interpretação física que proporciona aos performers podem ser tão importantes como os seus próprios níveis de significação (2000, p. 186).

Os objetos são pistas para brainstorming, apontando para um sentido intuitivo descoberto pela ação física. Assim, a intenção de quem originalmente escolheu o objeto é, recorrentemente, ignorada ou transformada pela intervençáo dos performers. É então importante notar que a manipulação dos objetos é sempre resultado de um compromisso entre membros da equipa criativa, assim como um compromisso entre as suas próprias características funcionais e estéticas e a sua nova condição teatral.

Estas "descobertas cenográficas", como Pamela Howard (2002, p. 102-103) as descreve, têm a capacidade de transformar de um modo imaginativo aquilo que nós assumimos como quotidiano ou comum através daquilo que poderíamos chamar de um toque de magia (teatral). Como com a magia, o que é fascinante é o fato que acontece 
perante os nossos olhos, "[...] dando a entender ao público que duas pequenas cadeiras possam representar uma vizinhança inteira'. Ao contrário da magia, onde o fazer aparecer e desaparecer com ilusão é fundamental, estas 'descobertas cenográficas' são interessantes sobretudo pela articulação inesperada que criam entre a dramaturgia e a cenografia. Uma articulação que é táo sugestiva como aberta a interpretação. O seu objetivo é o de criar uma possibilidade de relação entre diferentes fragmentos da performance e eventualmente entre a performance e o seu contexto. Mesmo se esta ligação se abre sobre um campo muito diferente de significaçáo.

\section{Objetos do Quotidiano}

Para Patrice Pavis, “[...] objetos reciclados são emprestados por uma realidade exterior e usados de uma forma estética num novo ambiente" (1996, p. 186). Esse autor considera que a função em performance, a origem material e a experiência estética desses objetos pelos espectadores, os permite dividir em três categorias: visual, olfativa e auditiva. Ele considera também que a associaçáo e interação de vários objetos pode formar um sistema que estrutura o ritmo da performance:

[...] do mesmo modo que o espaço, o objeto constrói frequentemente um sistema integrado, um ponto focal ou parâmetro para o resto da performance; o espectador aprecia-o como um ponto de referência, um marcador entre momentos ou espaços (Pavis, 1996, p. 186).

A experiência que o performer tem de um objeto do quotidiano ou objeto reciclado é ainda mais complexa, já que este tem de equilibrar a sua experiência individual da materialidade do objeto, com a experiência coletiva e a narrativa em desenvolvimento, estabelecendo um diálogo que sirva à performance. A experiência, em ensaio, de um objeto do quotidiano vem da relaçáo entre esse objeto e o seu utilizador humano. Essa conexão é construída a partir da observação e manipulação das características estéticas e funcionais de cada objeto. Em ensaio, os performers observam, manipulam e eventualmente modificam os objetos do quotidiano pela operação de gesto, ação e diálogo sobre as características originais do objeto.

Forma, cor e textura são qualidades materiais que nos permitem relacionar com um objeto e identificá-lo como útil para uma função ou ação específica, ou apenas como esteticamente agradável. A 
função ou propósito, o som produzido pelo objeto e o seu contexto sociocultural (para qual comunidade e profissão foi produzido e como é habitualmente utilizado) são características não-materiais. Estas são parte integral do objeto, providenciando informação adicional ao performer, que pode escolher usá-las como pretexto para o desenvolvimento do ensaio.

Note-se que o contexto sociocultural de um objeto é alterado no instante em que este é trazido para a sala de ensaios. Mesmo que performers e espectadores o associem a um contexto original específico, todos os objetos se transformam em objetos cênicos uma vez que tenham sido introduzidos no espaço de representaçáo (seja ele localizado num palco convencional ou náo). Tal como Aoife Monks (2010, p. 63) sugere:

[...] enquanto o pensamento empírico pode sugerir que as características observáveis dos objetos são de algum modo o meio para uma verdade, infelizmente essas mesmas características transformam-se, invariavelmente, 'não verdadeiras' quando colocadas em palco, são transformadas em características cênicas simplesmente pela sua inclusão no enquadramento da área de interpretação. A artificialidade e falsidade do teatro poderá levar à descoberta de um novo conjunto de verdades, verdades que só podem ser descobertas pelo teatro ou pela arte em geral, mas a noção de que objetos reais possam preservar a sua realidade quando inseridos em performance, é insustentável.

Os adereços de cena são todos cênicos, quer na sua origem quer quando começam a ser usados num contexto teatral. Os objetos construídos propositadamente para a cena são por natureza cênicos e, como tal, pertencem apenas ao contexto performático. Mesmo que todos os objetos usados em performance carreguem com eles a memória desse acontecimento, estes objetos não têm qualquer contexto anterior à performance. Em contraste, os brinquedos são um segundo tipo de adereço. Considerando que eles pertencem originalmente a um contexto de jogo, as suas características estéticas e funcionais são definidas justamente pelo ato de brincar. Visto que não existe um modo certo ou errado de jogar com um determinado brinquedo, é o ato de brincar que interessa tanto aos performers como aos espectadores. Finalmente, um terceiro tipo de adereço, os objetos do quotidiano são elementos cênicos pela intervenção dos performers e o simples fato de serem manipulados dentro do espaço de interpretação. Eles criam uma relação entre o significado associado ao seu contexto original e os significados desenvolvidos em performance: 
O objeto é capaz de funcionar desse modo porque é simultaneamente real e porque está sujeito à lei teatral de negação, não real. É duplamente real já que é, primeiro, uma presença real no espaço de representação e, segundo, porque faz relacionar atores e espectadores com um mundo real para lá do teatro, através da sua força de ação e de todas as conotaçôes que derivam das suas funçôes referenciais (McAuley, 2000, p. 181).

De fato, é o seu contexto pré-performance que sugere aos performers direções ou possibilidades para significação. É a tensão constante entre a sua origem e a sua recém-revelada condiçáo de objeto cênico que oferece aos performers modos de reposicionar a narrativa. Selecionando uma ou mais das suas características materiais e não materiais, listadas acima, como motivação, os performers investigam o objeto dentro do universo proposto pela performance. As suas intençóes podem mudar ao longo do tempo do ensaio ou pela interaçáo com outros performers ou membros da equipa artística. Assim, a transformaçáo de um objeto num adereço de cena vai evoluindo até, durante e depois do dia da estreia.

\section{Modificar o Quotidiano}

O processo de aplicação da imaginação ao quotidiano pode ser, como já foi mencionado, feito por gesto, ação ou diálogo, mudando a nossa percepção das características originais do objeto. Como Gay McAuley (2000, p. 198) diz:

[...] o gesto do ator liberta o objeto da sua função material e até substitui o objeto, criando a ideia do objeto desligado da sua realidade material; o teatro é, assim, capaz de separar significado do significante, mostrando ambos em conjunto com o gesto que os conecta/disconecta. [...] Cada adereço pode produzir um gesto diferente que pode levar à emergência de uma caracterização diferente.

O projeto Practice-as-Research (de investigação prática) Pequena História Trágico-Marítima, que desenvolvi com o encenador e dramaturgo Jorge Louraço Figueira, produzido pelo Teatro Acadêmico Gil Vicente, na Universidade de Coimbra, entre Janeiro e Junho de 2012, explorou quatro métodos pelos quais um performer pode ativar um objeto. A primeira modificação que um performer pode infligir num objeto é uma mudança na sua função (1): usá-lo de um modo que não esteja previsto pela sua função original, sem, no entanto, introduzir qualquer modificação nas 
suas características materiais. A segunda é uma alteração no som associado ou produzido pelo objeto (2), produzindo um novo som a partir do próprio objeto, do performer, ou de uma fonte externa. Esta pode ser acompanhada por uma transformação em função: um novo som pode introduzir uma nova função ou vice-versa. A terceira é uma alteração na percepção da escala de um objeto (3). Escala é dada inicialmente pela relação de proporção entre o objeto e o corpo humano, outros objetos envolventes e o espaço onde todos se inserem. Para que possa existir uma desassociação entre um objeto e a sua escala original, o performer precisa sugerir uma nova relação de espaço sem mudar a materialidade do objeto ou a sua própria massa corporal. A quarta é uma modificaçáo no equilíbrio entre as características materiais e não materiais de um objeto (4). Isto é, o performer escolhe amplificar as características estéticas de um objeto muito para lá das funcionais, atingido um ponto a partir do qual o objeto perde parte da sua identidade original e se torna difícil reconhecê-lo como um objeto do quotidiano. O objeto passa a ser então caracterizado apenas pela sua forma, cor e/ou textura, e claro pela sua interação em performance. Neste caso, é o próprio processo de transformação que se torna aparente enquanto que o quotidiano é progressivamente apagado.

Todas essas alteraçóes podem estar relacionadas, tanto como as características originais do objeto. Assim que uma é experimentada e operada, os performers podem achar outras interessantes. A sua adição e sobreposição ao longo do espetáculo pode transformar o objeto ao ponto de se tornar indistinto da açáo que o transformou:

Se a função do objeto foi transformada, muito embora o objeto ainda esteja presente na sua forma original, um outro nível de significado pode emergir à medida que os significados anteriores deixam um rasto nas funçóes que vão sendo introduzidas. Se o intervalo entre a atribuiçấo de duas funçóes diferentes ao mesmo objeto for muito longo, ou se um determinado objeto é sujeito a transformaçồes frequentes, então é o próprio processo de transformação que é trazido para primeiro plano (McAuley, 2000, p. 184).

É por tentativa e erro, em ensaio, que é feita a escolha de manter ou não estes grupos de ações. Essa escolha depende das características originais do objeto, da manipulação física e mental do performer e a capacidade desse mesmo performer de responder a um conceito ou narrativa específicos. 


\section{Do Ensaio ao Espetáculo}

Pequena História Trágico-Marítima envolvia o registro e análise dos diferentes estádios da criaçáo de uma cenografia, do conceito ao espetáculo, e suas relaçóes com a elaboração da dramaturgia. Esta produção é a narrativa de dois pescadores naufragados junto à costa da Nazaré (uma pequena aldeia piscatória em Portugal) e, enquanto procuram um modo de sobreviver, contam um ao outro histórias de aventuras passadas. A cenografia liderou as improvisaçóes e o texto foi introduzido tardiamente no processo criativo. Os exemplos desse espetáculo demonstram como um performer pode iniciar a transformação de um objeto do quotidiano num adereço de cena. Cada objeto descrito foi sujeito a uma série de operaçóes, todas relacionadas quer em sequência quer em simultâneo. Muito embora eu só vá olhar para os objetos do quotidiano, essa produçáo incorporava também objetos construídos propositadamente para a cena.

Os objetos do quotidiano foram introduzidos na sala de ensaios pela cenógrafa a partir de um conjunto de critérios desenvolvidos pelo encenador, os performers, e ela mesma durante os ensaios preliminares. Os objetos tinham de pertencer ao seu quotidiano; náo podiam contribuir para o salvamento imediato dos personagens; podiam ser alusivos ao Portugal dos anos 1970 e 80; podiam ter uma relação clara com a geografia e história da Nazaré - o que exporia o contraste ainda hoje existente entre as suas características rurais e industriais - e, finalmente, os objetos podiam ser alusivos a um conjunto de reaçóes físicas e psicológicas previsíveis na situação de naufrágio, como fome, sede, memória real e imaginada. De todos os objetos usados, eu escolhi apresentar três: um funil, uma mala de viagem e uma rede de pesca. Todos eles oferecem exemplos de múltiplos tipos de manipulação em diferentes fases do espetáculo.

O primeiro objeto que vou analisar é o funil (quadro a), como exemplo de alteraçáo de função e de som, pela manipulação de gesto e voz. Depois de uma observação inicial, os performers experimentaram com várias possibilidades de modificaçáo de função, usando-o como um megafone, como binóculos ou como um auxiliar de audição. 

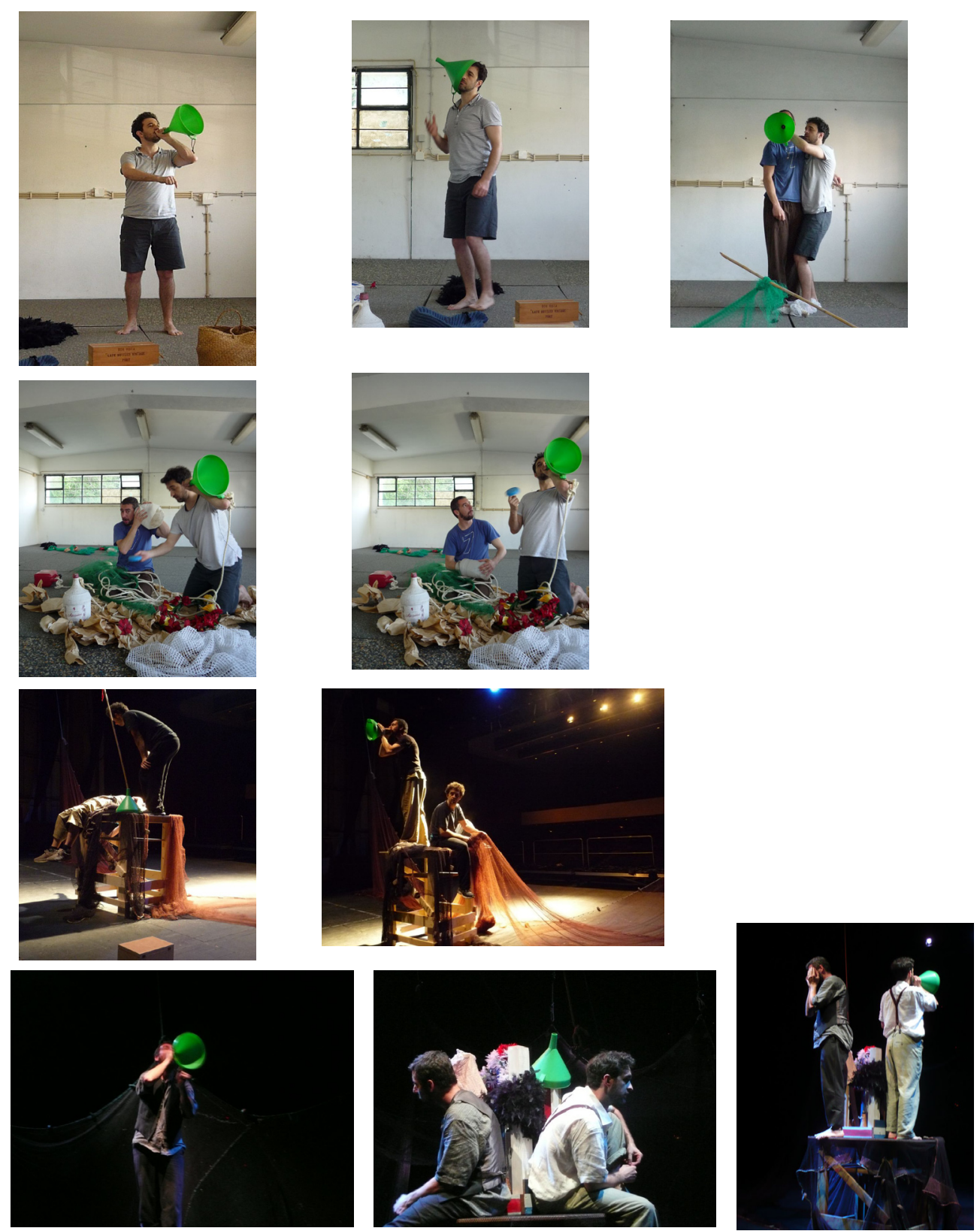

(a) Funil-exemplos da progressão deste objeto em ensaio (a preto e branco) e no espetáculo (a cores).

Muito embora todas estas açóes pudessem ser válidas, apenas uma respondia ao pedido pelo ensaio: encontrar um modo ativo para sobreviver ao naufrágio. Como binóculos ou como um auxiliar de audição, o objeto daria às personagens um modo passivo para a salvação - permitir-lhes-ia ouvir e ver, mas náo comunicar. A sua escolha, de usar o funil como megafone, foi resultado tanto do reconhecimento da forma original do objeto como da necessidade narrativa criada em ensaio. Assim que a voz foi adicionada à ação, a nova função do funil tornou-se aparente, assim como o seu processo de transformação, já 
que os performers tinham agora duas etapas para explorar: a primeira, o gesto de o levar à boca, a segunda, a amplificação das suas vozes. Num ensaio posterior foi introduzido um conjunto de sons exteriores a esta última ação: três músicas aparentemente estranhas ao contexto da performance e ao próprio objeto. Assim que o performer elevava o funil à boca, para chamar por ajuda, a música era ativada como resposta. Esta manipulaçáo era, no entanto, inadequada para essa fase do espetáculo, já que a confusão e incapacidade do performer em usar a sua própria voz no funil, nesse ponto do espetáculo, destruía o clímax de desespero pedido pela dramaturgia. No entanto, a sugestão de que o funil podia ser usado para introduzir uma voz independente das vozes das personagens, funcionando como um portal ou mediador entre a ficção e a subficção, foi recuperada mais tarde. O outro performer acabou por usar o funil para introduzir uma voz distorcida, sobre-humana, encenando um diálogo com a Virgem Maria, uma devoção da primeira personagem.

O segundo objeto, a mala de viagem (quadro b), foi introduzido tardiamente em ensaio como um adereço decorativo, ou seja, um objeto cujo único propósito cênico é oferecer um contexto para a personagem que o carrega. Neste caso, a mala é um signo claro de viagem. Assim que o performer a carregou para o palco, estabeleceu uma distinção entre os passados das duas personagens.
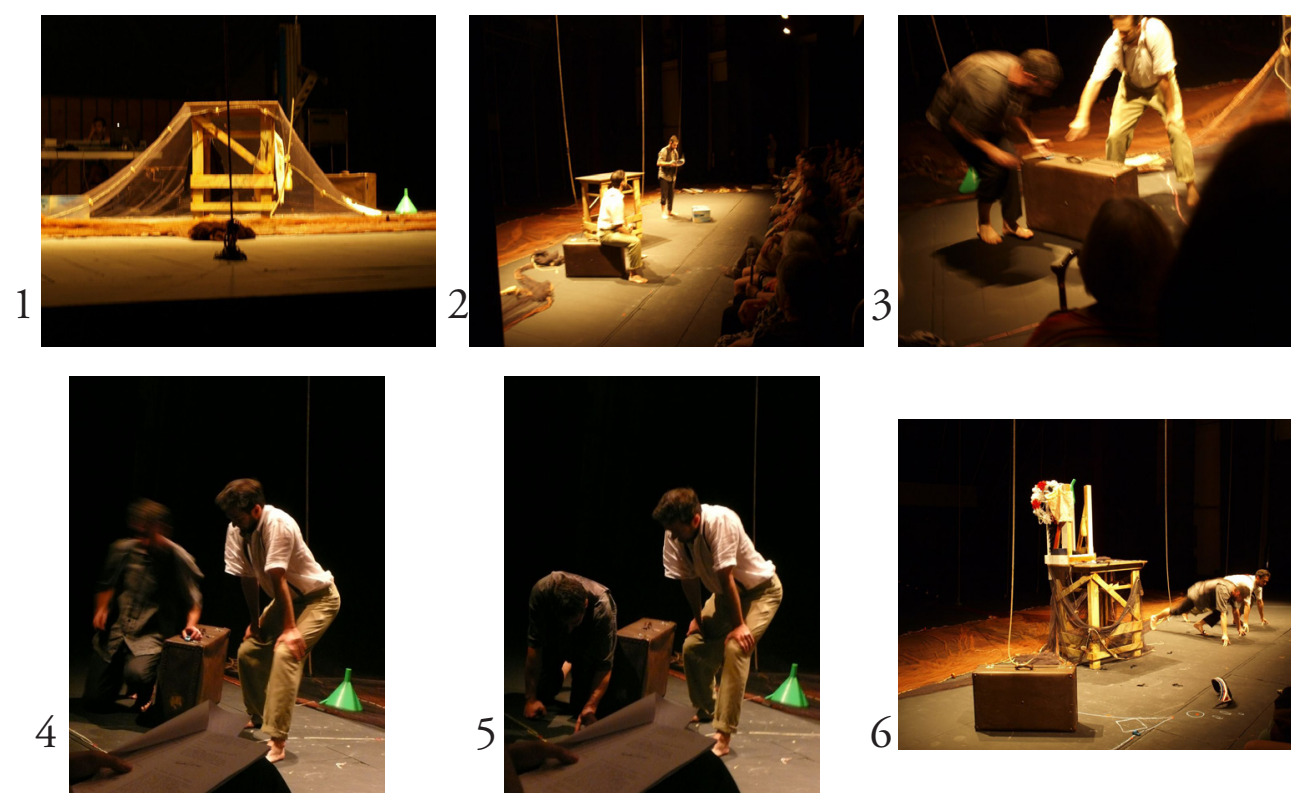

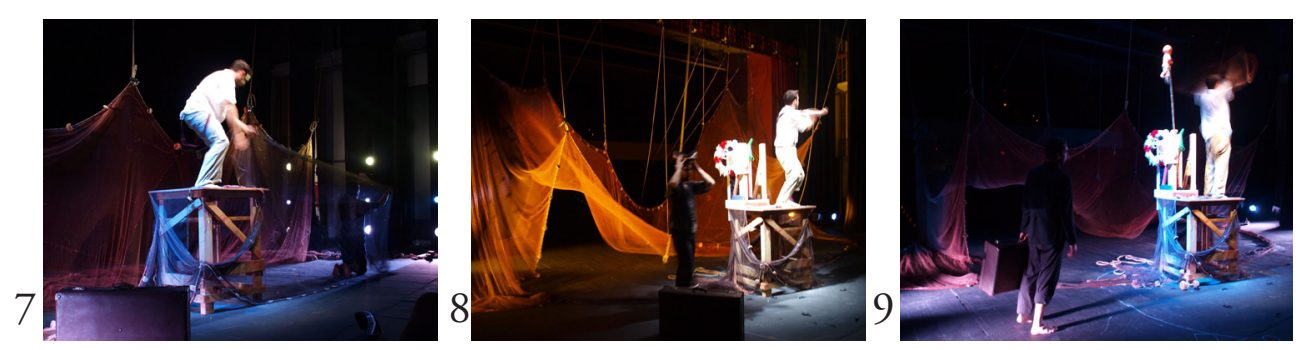

(b) Mala de viagem - exemplos da progressão deste objeto no espetáculo.

Depois desta cena (b2), o performer abandonou a mala em palco. Mais tarde, enquanto os performers desenhavam um mapa de giz no cháo do palco, a mala transformou-se num obstáculo (b3). O seu movimento da direita para a esquerda do palco, desenhando a linha de costa da Nazaré enquanto explicavam a relação intricada entre os bancos de pesca ao largo e os pontos de referência na vila, usados pelos pescadores para se orientarem (a taberna, a igreja, o santuário, o mercado, etc.), levava-os até ao rochedo onde o naufrágio tinha acontecido - por debaixo de um promontório coroado pelo farol. Em vez de mover a mala, um dos performers escolheu usá-la como o próprio promontório, adicionando-o como um elemento tridimensional do mapa. O pequeno carro brinquedo que os guiou através do mapa, subiu a mala de um lado e desceu do outro na direçáo da praia, modificando a nossa percepçáo da escala da sua escala, de um objeto do quotidiano feito para viajar para um elemento da geografia da Nazaré (b4 e b5), o lugar para onde a performance viaja. A medida que a ação continuou, a mala ficou para trás (assim como o carro-brinquedo e o barco-modelo), providenciando uma referência constante entre o naufrágio e a sua distância impossivelmente curta à costa e à segurança (b6). A ação estava concentrada em volta de uma mesa de onde os performers náo podiam escapar, um destroço no meio de um oceano. Simultaneamente, a distância entre os náufragos e o seu salvamento, vindo de terra, estava desenhada no cháo do palco, dando à performance um sentimento de urgência e de frustração que, de outro modo, poderia ter sido perdido para a imensidão do palco (b7). Finalmente, na última cena, a mala é retirada pelo outro performer (b9). É então a personagem que parecia estar em casa que a carrega para fora do palco, quebrando o mapa desenhado previamente e abandonando a cena. Esta mudança de mãos é também uma mudança de papéis: o viajante é o residente e, o residente, o viajante. Mas, visto que neste ponto do espetáculo a sua condição de náufragos já foi estabelecida e ultrapassada, a mala parece ambígua no seu significado: que tipo de viagem é esta? Este objeto do quotidiano foi manipulado pelo gesto e pela ação, 
modificando a percepçáo da sua escala, como forma de recolocá-lo em performance e amplificando o seu sentido. O objeto transformouse, por um instante, o gerador do espaço ficcional.

O terceiro e último objeto a ser analisado é a rede de pesca (quadro c). Este objeto é caracterizado por uma forma instável, maleável, capaz de se sujeitar às intençóes dos performers. As suas cores e textura são muito facilmente modificadas pela iluminação de cena. Consequentemente, o seu controle em espetáculo implicou uma prática intensa e disciplinada. Durante a maioria dos ensaios os performers usaram uma rede menor como substituta da vasta rede de pesca que foi mais tarde adicionada à teia do palco.
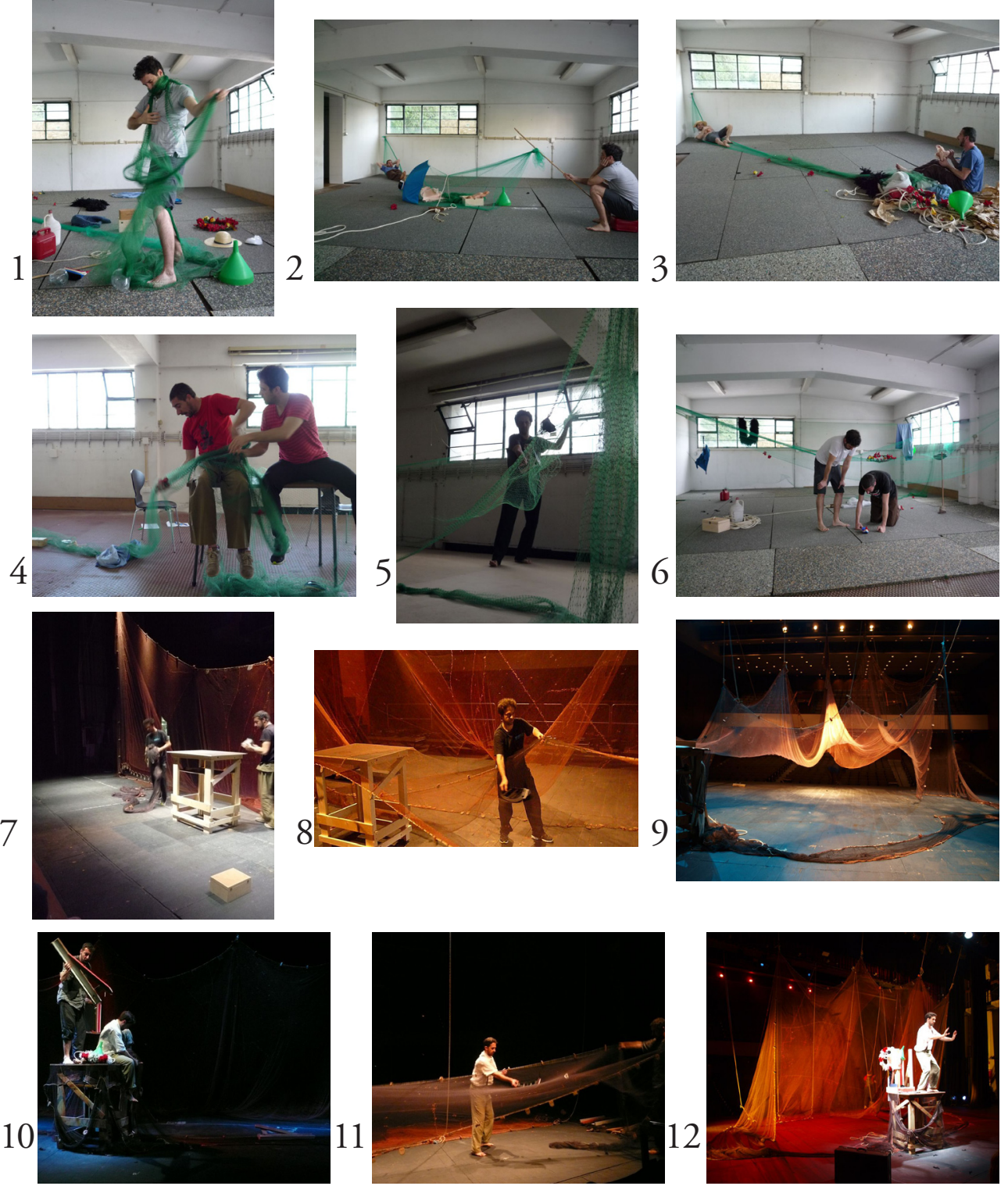

(c) Rede de pesca - exemplos da progressão deste objeto em ensaio (a preto e branco) e no espetáculo (a cores). 
Esta rede menor permitiu-lhes explorar forma, função e movimento, incorporando o conhecimento do seu contexto original (a comunidade de pesca) com os objetivos da narrativa proposta (c4). Pela sua natureza plástica, este tipo de rede pede uma manipulaçáo metódica e rigorosa: é muito fácil de enrolá-la em volta do corpo, ou mesmo perder a noção do que arrasta em palco (c1). No entanto, é a sua flexibilidade, e também o fato de poder ser tão pequena que caiba num cesto ou tão grande que 'engula' a ação de todo o palco, que lhe permite transformar completamente o espaço de performance. Mesmo que a sua função primária (um tecido de malha aberta usado para agarrar, apanhar e transportar algo ou alguém) tenha sido mantida ao longo de todos os ensaios e espetáculo, o método pelo qual era posta em prática e o modo pelo qual interagia com os performers e outros objetos, variou. Os performers brincaram com a ideia de se sentirem presos por ela (c1). Neste caso a rede tomou a forma do corpo do performer, e ganhando vida com o seu movimento. $\mathrm{O}$ fascínio estético dessa interação é equilibrado pelo conhecimento de que esta também é uma situação perigosa para a personagem. Essa manipulação, assim como a ideia de usar a rede como uma linha de pesca (c2, c3 e c4), foi mais tarde incorporada no espetáculo como uma forma de salvar tanto performers como objetos das águas envolvendo o naufrágio (c10). Esse processo permitiu que várias áreas do espaço de representação estivessem fisicamente ligadas. Os performers podiam ativar setores múltiplos do palco mesmo quando estavam confinados ao destroço/mesa. Quando a rede de pesca real maior foi introduzida, performers, cenógrafa e encenador perceberam que o seu tamanho permitia manipulaçóes múltiplas e simultâneas. Visto que a rede envolvia todo o espaço de performance, podia ser também operada de vários lados, quer em cena quer fora dela. Mesmo que a funçâo original do objeto (pescar) tenha sido obviamente impossível de replicar em palco, a sua gestualidade era sugerida e feita teatral, simplesmente porque fazia parte do espaço de representação.

Uma outra sugestáo era usar a rede como um fundo e suporte para um pequeno modelo de barco (c5). Este barco fazia parte de um conjunto de adereços construídos propositadamente para o espetáculo. É uma pequena réplica de um barco de pesca característico da Nazaré. Uma vez equilibrado num pedaço de rede bem esticada, ganhou vida, navegando. A mudança na percepção da escala da rede, pela introdução do barco, transformou-a num oceano, e a sua textura 
e imprevisibilidade de movimento levaram esta sugestáo ainda mais longe (c8). Os performers tentaram controlar a sua forma e direção num esforço de manter o barco a deslizar e de pé, usando este ato de circo para demonstrar o delicado equilíbrio entre o seu modo de vida e a sua morte. Mais uma vez, a cena foi encenada usando apenas uma das pontas da rede de pesca, enquanto o resto se mantinha espalhado no palco (c11). O adereço era, simultaneamente, objeto e ambiente, duas partes da mesma narrativa. Os ensaios também revelaram a capacidade da rede para servir como um fundo ativo para a ação (c6). Os performers usaram-na como cabide para outros adereços, percebendo que a rede se podia transformar numa personagem independente da ação se manipulada fora de cena. O diálogo produzido entre as açóes dos performers e as formas, texturas e cores sugestivas dadas pela rede, amplificavam a cena (c13). As qualidades estéticas da rede eram manipuladas e sublinhadas ao ponto de, por um instante, se transformar num objeto abstrato da composição cenográfica (c9). A perda temporária de todos os seus objetivos funcionais transformaram-na numa evocação dos gestos, das açóes e dos diálogos dos performers. As formas que tomou respondiam a memórias de sítios ou situaçóes que as personagens tinham vivido: um cinema (c12), um bordel e as colinas do Rio de Janeiro (c9).

\section{Conclusão}

A rede de pesca era uma presença constante no espetáculo. Estruturava tanto o espaço como o tempo da performance, organizando o espaço de interpretaçáo, influenciando, consequentemente, a marcação da maioria das cenas e oferecendo possibilidades múltiplas para a expansão do espaço ficcional. De cada vez que o espaço ficcional era estendido para lá do espaço de representação, emergia um novo caminho dramatúrgico, abrindo a performance a diversas narrativas. Mesmo que este último objeto seja essencial para a concepção do espaço de performance, todos os objetos discutidos demonstram a capacidade do objeto para a composição de espaço. O exemplo descrito por Peter Brook, citado por Andrew Todd, explica:

Se o espaço estiver absolutamente vazio, parece-nos que as possibilidades coreográficas para teatro são exauridas muito rapidamente. $\mathrm{Na}$ dança isto não é um problema porque náo existe um limite para as formas que um corpo pode tomar, mas com a interpretação teatral a variedade é muito 
menor - os atores, ao contrário dos bailarinos, não conseguem formar imagens bonitas. [...] Em Hamlet, percebemos que precisávamos de objetos para articular o espaço, para instalar diagonais, movimentos circulares, de forma a que as pessoas pudessem estar mais próximas, ou mais afastadas [...] Percebemos [...] que tudo o que precisávamos era que alguém movesse uma cadeira ou a virasse ao contrário para que a cena se modificasse completamente, indicando que nos situávamos num outro espaço (2003, p. 229).

Um objeto ou um grupo de objetos pode sugerir ou indicar uma mudança no espaço ficcional e uma reorientação da narrativa que o anima. Eles o fazem, em primeiro lugar, por serem objetos e, como tal, portadores de características específicas, e em segundo, quando sáo ativados pelos performers. A combinação destes dois aspectos provoca uma deslocação espacial poderosa durante o processo criativo $\mathrm{e}$, mais tarde, em performance. $\mathrm{O}$ processo pelo qual os objetos do quotidiano envolvem a imaginação performativa podem ser variados e complexos, mas invariavelmente criam uma interdependência entre a cenografia e a dramaturgia que realça a realidade dentro e fora do palco. 


\section{Referências}

COLLINS, Jane; NISBETT, Andrew (Org.). Theatre and Performance Design: a reader in scenography. Oxford: Routledge, 2010.

HOWARD, Pamela. What is Scenography? Oxford: Routledge, 2002.

MCAUlEY, Gay. Space in Performance: making meaning in the theatre. Ann Arbor: University of Michigan Press, 2000.

MONKS, Aoife. The Actor in Costume. Hampshire: Palgrave Macmillan, 2010.

PAVIS, Patrice. Analysing Performance: theatre, dance and film. Ann Arbor: University of Michigan Press, 1996.

PAYNE, Darwin Reid. Scenographic Imagination. Carbondale e Edwardsville: Southern Illinois University Press, 1993.

READ, Alan. Theatre and Everyday Life. Oxford: Routledge, 1993.

TODD, Andrew; LECAT, Jean-Guy. The Open Circle: Peter Brook's theatre environments. Nova Iorque: Palgrave Macmillan, 2003.

Filipa Malva formou-se em cenografia pela University of Kent, na Inglaterra. Trabalhou para o Teatro Nacional de São Carlos e a Royal Opera House, em Londres. Tem colaborado em Portugal com a Avalon Theatre Company, os Lisbon Players, $O$ Teatrão, $O$ Bando e a Bonifrates. Tem uma experiência alargada em desenho e pintura cênica e é docente de Estudos Artísticos na Universidade de Coimbra, onde prepara o seu doutoramento.

E-mail: filipamdv@gmail.com

Recebido em 03 de novembro de 2012 Aprovado em 07 de abril de 2013 